\title{
THE OCCASIONAL "INDEPENDENCE" OF DYSLEXIA AND DYSGRAPHIA FROM DYSPHASIA
}

BY

\section{T. CASEY and G. ETTLINGER}

\author{
From the National Hospital and Psychological Department of the Institute of Neurology, \\ Queen Square, London
}

In spite of the opportunity afforded by neurological cases for the study of the association of reading, writing, and spoken speech disorders, there is little agreement on the question whether these disabilities may exist independently or are necessarily parts of a general language disturbance. Where a disorder of reading has been found to be the major disability it has been accepted by some authors as a partial agnosia or a selective symbolic defect (Holmes, 1950; Symonds, 1953; Brain, 1955). On the other hand Critchley (1953) has held that such a dyslexia forms part of a more general disorder of language, as shown by the concomitant minor grades of speech defect. Other authors have sought to explain similar cases of reading disorder on the basis of fluctuating visual sensory efficiency (Beringer and Stein, 1930), of visual disorientation (Martin, 1954), or of alterations of eye movements (Warrington and Zangwill, 1957). However, another disability seen even more frequently in association with dyslexia, defective identification of colours, has not been thought to give rise to the disorder of reading.

Dysgraphia has been accepted by some authors (e.g., Gerstman, 1940) as a disability that can be seen without disturbances of spoken speech and reading. Critchley (1953) has sought to explain this form of dysgraphia as a disability of execution, a dyspraxia for writing. Again, it is noteworthy that the other features of the Gerstman syndromedyscalculia, finger agnosia, and right-left disorientation-are not invoked to explain the dysgraphia. It is, moreover, plausible that these are the results of proximity of functional areas rather than bearing any functional inter-relationship.

In the present paper we wish to present further evidence for the occasional "independence" of dyslexia and dysgraphia from dysphasia, first, by a conventional detailed report of one patient; and second, by a survey of a series of unselected cases of language disability. For this purpose we refer to dyslexia as the inability to read correctly words and letters aloud; dysgraphia, as the inability to write correctly on paper; and dysphasia, as a defect of spoken speech as conventionally assessed by clinical testing.

\section{Case Report}

Clinical History.-A theatrical entertainer (R.H., N.H. 84427), aged 45, was admitted as an emergency to $\overline{\overline{3}}$ the National Hospital, Queen Square, on February 25, 1959, under the care of Dr. Carmichael. Five days previously while sitting quietly and reading, he suddenly $\dot{\omega}$ experienced severe, throbbing, bifrontal headache is Shortly after, he vomited twice and was aware of diff culty of seeing to the right, diplopia, and an inability to read. Unassisted he visited his physician who pres scribed rest and an unknown medication. He did not experience disorientation or motor dísability. During the next few days moderately painful headaches recurre $\phi$ Reading remained affected as did the difficulty in seeing things to the right. He had a second episode of severe $\vec{\theta}$ headache similar to the first on the day of admission During admission no obvious signs of illness were seen. He dressed in hospital attire and got into bed with the facility of a healthy individual.

Clinical Examination.-He was a rather florid, slightly obese, right-handed man. Temperature was $98 \cdot 4^{\circ} \mathrm{F}$., pulse 80 , respirations 20 , blood pressure $140 / 90 \mathrm{~mm}$. $\mathrm{Hg}$. No abnormalities were found outside the central nervous system.

Spontaneous spoken speech was normal, the account of the illness being told with clarity and ease. Direct questioning requiring specific responses revealed several abnormalities. There was partial disorientation in time. With complex, but not with simple, instructions he had difficulty in identifying parts of his body, and in performing other actions. Naming of objects showed a tendency to perseveration. He was unable to read or spell aloud single words. Writing to dictation was grossly abnormal. Spontaneous writing, although inaccurate, was not as severely impaired.

When first examined the skull was considered normal. On re-examination following carotid arteriography, a pulsatile left occipital artery was palpable and a lowpitched, continuous bruit could be heard in a quiet room. The neck was moderately rigid with a positive Kernig's 


\section{"INDEPENDENCE" OF DYSLEXIA AND DYSGRAPHIA FROM DYSPHASIA}

sign. Examination of the visual fields demonstrated a right homonymous hemianopsia. A light could just be discerned in the right lower quadrant but was invisible in the quadrant above. Moving objects (such as the hand) could not be seen in either quadrant. The right pupil was slightly larger than the left. Both reacted briskly to light and on convergence. Fundi were normal. Visual acuity tested with the illiterate " $E$ " chart was $6 / 9$ in the right eye and $6 / 6$ in the left. There was no diplopia or nystagmus. Other cranial nerves were normal. No abnormality of power, tone, coordination, development, or reflexes was observed. A suggestion of astereognosis in the right hand was the only sensory abnormality.

Investigations.-On February 25, 1959, urine was normal. Cerebrospinal fluid pressure was $170 \mathrm{~mm}$. C.S.F. with a free rise and fall, and the fluid appeared cloudy. There were 2,100 leucocytes per c.mm. of which $90 \%$ were polymorphonuclear. Erythrocytes were 1,600 per c. $\mathrm{mm}$., the protein $140 \mathrm{mg} . \%$, glucose $47 \mathrm{mg} . \%$. Culture showed no growth at 18 and 36 hours. No tubercle bacilli were found by smears.

An opaque right antrum was the only abnormality on radiographs of the skull. The chest radiograph was normal. Left carotid arteriography (Dr. R. S. C. Couch) demonstrated an arteriovenous malformation in the left occipital region which appeared to be fed by a large left occipital artery (Fig. 1). The anterior cerebral artery was shifted about $5 \mathrm{~mm}$. to the right of the midline. The possibility of a left-sided haematoma was raised. No other abnormalities were seen. The presumptive diagnosis of haemorrhage from an arteriovenous malformation was made.

Subsequent investigations were as follows:

On February 29 the cerebrospinal fluid appeared faintly yellow and there were 10 leucocytes per c. mm., 7 of which were lymphocytes, and 3 large monocytes; protein $80 \mathrm{mg} . \%$.

On March 12 it was yellow and clear, lymphocytes 5 per c. mm., protein $90 \mathrm{mg} . \%$.

An E.E.G. on March 3 (Dr. E. Poole) showed a moderate disturbance in the left temporal area most obvious anteriorly but possibly extending well back because of the alpha asymmetry. A second E.E.G. on March 17 (Dr. E. Poole) showed no significant change although the right-left asymmetries seemed less prominent and the slowest components less obvious.

An otological examination on March 20 (Dr. M. R. Dix) reported findings in accordance with a lesion of the left cerebral hemisphere affecting the supra-marginal and angular gyri or their central pathways.

Progress.-Complete bed rest and symptomatic therapy were ordered.

Headaches subsided until the evening of March 5 when a moderately severe occipital pain lasted for several hours. Next day he had no complaints. Again on March 9 he had a more severe headache, mainly left supra-orbital but extending back to the occiput on the same side. It lasted for about three hours causing the patient considerable distress. With each headache, the language disorders became temporarily more pronounced. On the

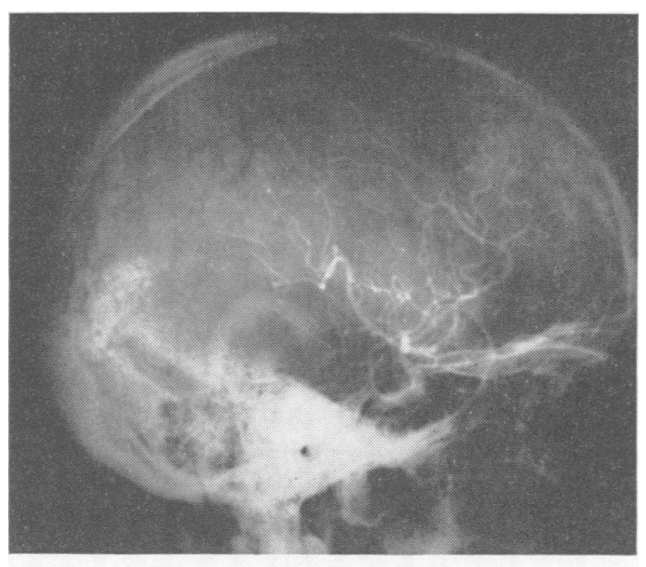

FIG. 1a

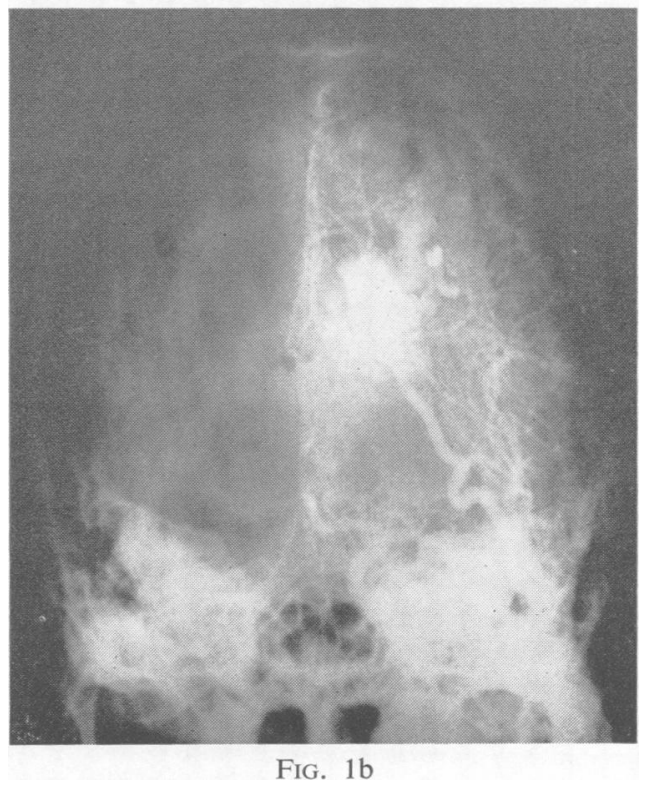

FIG. 1a and b.-Left carotid angiography shows in the left occipital lobe a vascular anomally fed by the occipital artery.

following day he appeared to have returned to the previous level of improvement.

Neck rigidity disappeared in the first few days after admission but the field defect was unchanged. After three weeks, short periods of ambulation were permitted and gradually all normal activity was resumed. On the day of discharge (March 26) he was free from headache but still retained some difficulty in reading.

Follow-up.-The patient was re-examined on July 21, 1959. His clinical condition was unchanged except for an improvement of visual acuity to V.A.R. 6/5 and V.A.L. $6 / 5$. 
On December 8 re-examination showed splitting of the macula with the right hemianopsia but no other change.

Psychological Examination.-The patient was tested daily (excepting Sundays) between February 26, 1959, and March 20,1959, and he was again seen on March 26, July 21 and 22 , and on December 8,1959 . He was always cooperative and never appeared depressed or especially anxious. He did not tire easily during testing.

Intellectual Testing.-The patient's intellectual proficiency was assessed on most of the subtests of the Wechsler-Bellevue scale and also in various other ways. Verbal tests indicated moderate impairment. Thus he scored above average on the vocabulary subtest (weighted score of 14 on March 14, 1959), but below average on similarities (weighted score of 6 corrected for age on March 6) and also on digit span (weighted score of 8 on March 6). He failed to learn the Babcock sentence in eight trials both on February 27 and March 12, but made only one error in his last two attempts on the latter date. He repeated it correctly after six trials on March 26. His interpretations of proverbs were mildly impaired as also was his memory for events of general interest and for their dates on March 4.

When he was retested on July 22 there was evidence of consistent improvement. Thus his score on the similarities test had risen to 12 and on digit span to 9 .

In general his performance on non-verbal tests was rather better. Thus he scored close to the average on the picture completion subtest (weighted score of 11 on March 2), on picture arrangement (weighted score of 9 on March 16), and on block designs (weighted score of 9 on March 13). Interestingly, he scored well below the average on the digit symbol subtest (weighted score of 6 on March 14). He passed Weigl's sorting test on February 28 and was able to give fair to good interpretations of pictures and pictorial absurdities (Terman scale) on February 27. He was tested on three sets of Raven's matrices on March 13 and gave answers which would suggest a level below the average. His performance on the memory for designs test (Terman M scale) on March 4 was probably also impaired (score of 1 where maximum obtainable is 2).

There was improvement also on non-verbal tests when he was retested on July 22 . His score on picture completion was now 15 , on picture arrangement 10 , on block designs 11, and he scored 8 on the digit symbol test.

His ability to calculate was severely defective. Both mental and written arithmetic were affected. Thus he gave only two correct answers on the arithmetic subtest of the Wechsler-Bellevue scale (weighted score of 2 on March 16) and failed in every instance when required to solve simple written sums involving addition, subtraction, multiplication, or division on March 2 and March 13. By contrast he was able to count scattered objects and assemble given numbers of objects without error on February 28.

This severe initial disability had largely improved by $\vec{\circ}$ July 22. His score on the arithmetic subtest was now 10 and he was able to solve all simple written sums correctly.

Spoken Speech.-At no time was there a severe dysphasia. The patient's moderate to minimal speech disturbance became apparent only through the occa- in sional use of an odd word between February 26 and March 2, and by his subsequent occasional loss for a word $\omega$ and on formal tests of naming objects. He gave $84 \% \mathrm{~N}$ correct responses when required to name objects from 9 standard test series on February 27 and then improved $100 \%$ correct with the same series on March 6 . Howeve when required to find a name by definition (using the microscope, telescope, stethescope, periscope type \&f을 series) he scored $83 \%$ correct on February 27 and on of $86 \%$ correct on March 12 . At this time he was also st再 unable to find the name of some few uncommon objects pointed out to him.

His nominal disability had further improved by July 21 but he was still slow when required to find names by definition, and he was not able to name the buckle on a

TABLE I

PROGRESSIVE IMPROVEMENT OF INTELLIGENCE TEST SCORES IN CASE R.H.*

\begin{tabular}{|c|c|c|c|c|}
\hline $\begin{array}{l}\text { Wechsler-Bellevue } \\
\text { Scale I Tests }\end{array}$ & February 26-March 4 & March 5-11 & March 12-18 & July 21-22 \\
\hline $\begin{array}{l}\text { Vocabulary } \\
\text { Similarities } \\
\text { Digit span } \\
\text { Arithmetic } \\
\text { Picture completion } \\
\text { Picture arrangement } \\
\text { Block designs } \\
\text { Digit-symbol }\end{array}$ & $\begin{array}{l}\overline{-} \\
\overline{11} \\
z\end{array}$ & $\begin{array}{l}\overline{6} \\
8 \\
= \\
=\end{array}$ & $\frac{14}{\frac{1}{2}}$ & $\begin{array}{r}12 \\
12 \\
9 \\
10 \\
15 \\
10 \\
11 \\
8\end{array}$ \\
\hline
\end{tabular}

* The figures represent weighted scores corrected for age.

TABLE II

PROGRESSIVE IMPROVEMENT OF SPOKEN SPEECH IN CASE R.H.

\begin{tabular}{|c|c|c|c|c|c|c|c|}
\hline & Feb. 26-Mar. 4 & Mar. 5-11 & Mar. 12-18 & Mar. 19-25 & Mar. 26 & July $21-22$ & Dec. 8 \\
\hline $\begin{array}{l}\text { Expressive defect } \\
\text { Receptive defect } \\
\text { Nominal defect }\end{array}$ & $\begin{array}{l}\text { None } \\
\text { Slight } \\
\text { Moderate }\end{array}$ & $\begin{array}{l}\text { None } \\
\text { None } \\
\text { Slight }\end{array}$ & $\begin{array}{l}\text { None } \\
\text { None } \\
\text { Slight }\end{array}$ & $\begin{array}{l}\text { None } \\
\text { None } \\
\text { Slight }\end{array}$ & $\begin{array}{l}\text { None } \\
\text { None } \\
\text { Slight }\end{array}$ & $\begin{array}{l}\text { None } \\
\text { None } \\
\text { Minimal }\end{array}$ & $\begin{array}{l}\text { None } \\
\text { None } \\
\text { Minimal }\end{array}$ \\
\hline
\end{tabular}


watch-strap when tested on a series of 20 objects. His performance was unchanged on December 8.

Comprehension of speech was initially a little slower than might be expected but never gave rise to mistakes. When tested formally on March 5 with some of the complicated instructions from Burt's series (given orally) he made no error. There was no expressive speech disturbance.

Reading.-The patient's disorder of reading was initially severe but had improved considerably by March 20 and could be detected only by careful testing on March 26, July 21, and December 8 . He found it more difficult to read letters than words, but reading of every kind of written material, excepting only musical notation, was affected to some extent. The patient was fully aware of his disability and of its consequences, and made efforts to improve his reading by practice.

His reading of single letters was tested in a variety of ways. Written or printed capital letters were all read incorrectly on February 27 but correctly in $50 \%$ of attempts on March 2, in $85 \%$ on March 13, and in $100 \%$ on March 26 and July 21 . On December 8 he read $P$ for $F$. He still made one error, mistaking a $p$ for a $g$, in reading a random alphabet of small printed letters on March 26 and a different mistake (1 for i) on July 21 and December 8. When he was asked to read capital letters that formed part of words which he had just previously read correctly he obtained scores of $82 \%$ correct on March 4 and $91 \%$ correct on March 17 . Letters that had been written by himself he read correctly in $55 \%$ of attempts on March 4 and in $100 \%$ on March 17. He found large plastic (solid) capital letters no easier to read than printed letters, since he scored only $40 \%$ correct on March 3 and $80 \%$ correct on March 11 . On July 21 he made no error. He scored $74 \%$ correct on March 3 and $80 \%$ on March 11 when asked to select a given (named) letter from among 10 scattered solid letters. On July 21 he was slow and doubtful when asked to find the letter $Y$, but otherwise made no mistakes.

When printed words were offered singly he read $17 \%$ correctly on February $27,80 \%$ correctly on March 9 , and $92 \%$ on March 26 . On this date he still misread it for at, wil for wit, jim for dim, mop for mob, and tape for tap. There was only one error (in 100 words) when he was tested with the same series on July 21 . His reading standard for words was equivalent to that of the average 11-year-old child (by Burt's scale) on March 17 and also on December 8 . Only $40 \%$ of words forming part of short sentences were read correctly on March 2 but this improved to $97 \%$ on March 13 . Words forming part of connected passages of prose were rather easier for him to read $(80 \%$ correct on March 4 and $97 \%$ correct on March 17). However, only $80 \%$ of single words formed of solid letters were read correctly on March 11 .

The patient was able to comprehend correctly, although rather slowly, the meaning of written words. This was tested by displaying a number of objects and requiring the patient to read silently from a list one name at a time and then to point to the appropriate object. No error was made on March 9 or on July 21 in 10 trials on which the words had been correctly read. However, neither on March 5 nor on March 17 was he able to comprehend or correctly perform written instructions (taken from the 7- and 10-year levels of Burt's scale). This difficulty may merely have reflected his inability at this time to read sentences or longer passages without error rather than a genuine disorder of comprehension. The same instructions were correctly comprehended on July 21 .

He made many errors initially in reading both arabic and Roman numerals, but improved rapidly in the case of arabic figures, from $0 \%$ correct on February 27 and $25 \%$ correct on March 2 to $100 \%$ correct on March 13 and March 26. His score with Roman numerals varied between only $10 \%$ and $30 \%$ correct right up to July 21 , and may indeed reflect, as he claimed, a long-standing unfamiliarity with this notation. Other symbols, such as the multiplication, percentage, exclamation signs, and the sign of the London Passenger Transport system also gave rise to difficulty $(71 \%$. identified correctly on March 2, $60 \%$ on March $13,63 \%$ on July 21 , and $70 \%$ on December 8), and he was unable to read the clock correctly in more than about two-thirds of trials on March 3, March 18, and July 21. He was slow, but made no errors in reading the time on December 8. Atypically, he found it more difficult to identify letters and numerals traced on to the palm of his hand or on to his forearm than to read visually. Thus he failed at all attempts on February 27 and correctly identified letters in only $50 \%$ of trials and of numbers in only $44 \%$ on March 9 and in $30 \%$ on July 21 . Solid plastic letters were recognized by touch alone (both hands) in $35 \%$ of attempts on February 27 and in $70 \%$ on March 11 .

In contrast to his defective recognition of letters, words, symbols, and numerals was his ability to read musical notation apparently as well as he had ever done so. He had in fact never studied music but learnt a rhyme which enabled him to read certain notes. These, with one mistake, he identified with apparent ease on March 2. He read not very distinct flat and sharp notations quite easily, scoring $94 \%$ correct overall for musical notation. On March 5 and March 20 he was asked to make written records of short rhythms tapped with a pencil on a table. His records were correct within the framework of his own notation in $80 \%$ of attempts on both of these dates. When asked thereupon to reproduce the rhythms by tapping and reading from these written records, he successfully interpreted his own notation in $90 \%$ of trials on March 5 and in $100 \%$ on March 20.

It was not easy to analyse the disorder of reading because there was such rapid improvement from almost total loss to good proficiency between February 27 and March 26. Nevertheless, some qualitative observations are of interest. The right-sided field defect was probably of only initial importance. Thus, on February 27 when given a matrix of words (with horizontal lines and vertical columns) he read down the left-hand column rather than across the top line. However, by March 4 he had learnt to allow for his field defect when reading and no longer gave evidence of actual neglect of material to the right of his fixation point. Nevertheless, even as late as on March 17 and July 21 he was still making more mistakes 
TABLE III

PROGRESSIVE IMPROVEMENT OF READING IN CASE R.H.*

\begin{tabular}{|c|c|c|c|c|c|c|}
\hline & Feb. 26-Mar. 4 & Mar. 5-11 & Mar. 12-18 & Mar. 26 & July 21-22 & Dec. 8 \\
\hline $\begin{array}{l}\text { Capital letters } \\
\text { Small letters }\end{array}$ & $0-50$ & 80 & $\begin{array}{l}85 \\
85\end{array}$ & $\begin{array}{r}100 \\
96\end{array}$ & $\begin{array}{r}100 \\
96\end{array}$ & $\begin{array}{l}96 \\
96\end{array}$ \\
\hline Words (single) & 17 & 80 & $\frac{1}{0-1}$ & 92 & 99 & - \\
\hline Words (connected) & $40-80$ & 85 & 97 & - & - & $\overline{0}$ \\
\hline Numerals (arabic) & $0-25$ & 40 & 100 & 100 & $\overline{19}$ & 100 \\
\hline $\begin{array}{l}\text { Symbols } \\
\text { Music }\end{array}$ & $\begin{array}{l}71 \\
94\end{array}$ & - & 60 & 二 & 63 & 70 \\
\hline Finding given letter & 74 & $\overline{80}$ & - & - & 100 & - \\
\hline
\end{tabular}

* The figures represent the percentage of correct responses.

with the ends especially of polysyllabic words than with their beginnings (reading university for universal, know for known, perpetuate for perpetual, apprehend for apprehensive, etc.). The field defect cannot, of course, account for his difficulties with single letters and numerals. It appeared that certain letters e.g., F, S, and G, gave rise to especial difficulty when the remainder could already be correctly identified once again. Tracing the outline of letters with his finger did not help in their identification. On March 26 he was carefully questioned about his disability: "The words didn't mean anything.The shapes definitely seemed familiar. Given Greek and Latin letters mixed I would have known which were which.-The sounds belonging to the letters did not get confused. I got stuck on the visual side.-(Given a word he still could not read). The end of this word does not register, I do not get the meaning.-The sound has nothing to do with it."

Writing.-The patient was able to write most but not all capital letters to command, scoring $80 \%$ correct on March 4 and $96 \%$ on March 18. His copies of capitals were $90 \%$ correct on March 6 and $100 \%$ on March 9. Transcription from capitals into script was, however, more difficult $(50 \%$ correct on March 9 and $100 \%$ on March 20).

His ability to write single words to dictation was rather variable. Thus he achieved $60 \%$ correct on March 9 with one series, but only $10 \%$ correct on March 17 with another series (taken at the 10-year level from Burt's oral spelling test). On July 21 and December 8 he was still making errors at the 12-year and subsequent levels on this test. He was unable to compose any one word without error on March 5 when asked to use solid capital letters. Single words were copied correctly in $\mathbf{8 0} \%$ of attempts on March 20 but transcribed correctly from capitals into script in only $60 \%$ of attempts using the same materials on the same date. Very similar results were obtained with sentences when the patient was required to write to dictation, to copy, or to transcribe. Both copies and transcriptions were faultless by July 21 . In spontaneous writing $68 \%$ of words were correct on March 2 and $83 \%$ on March 13. Various samples of the patient's writing are shown in Fig. 2.

There was also a severe defect of oral spelling. Thus only $35 \%$ of words were correctly spelled on March 3 and on March 19 the patient's spelling age was only 12 years by Burt's standardization. This improved to 13 to 14 years by July 21 .
As in reading, so the writing of arabic figures was at first severely impaired (none correct on March 4) but $\frac{\bar{\sigma}}{}$ recovered rapidly $(100 \%$ correct on March 18 and July $\overline{\bar{\sigma}}$ 21). Copies of arabic figures were correct in $60 \%$ of $\overrightarrow{\mathbb{D}}$ attempts on March 6, in $90 \%$ on March 9, and $100 \%$ on March 18. He claimed that he had never properly learnt how to write Roman numerals.

Executive Functions.-There was no evidence of any $\overrightarrow{\vec{t}}$ kind of apraxic disorder (other than on constructional $\vec{\omega}$ tests, which are to be considered separately).

Perception.-The patient made no errors when tested on March 4 for right/left orientation and finger identifica-iv tion on his own person. He was equally proficient when $\omega$ tested in the same way on the examiner's person, excepti when the examiner crossed his hands, sitting face to fade $\infty$ opposite the patient: under these latter conditions af $\mathrm{O}$ testing the patient was occasionally confused, especiaby as regards the laterality of the examiner's crossed hands. On March 9 he was asked to identify various parts of the body by name (autotopgnosis) and made only one error (in saying knuckle for wrist).

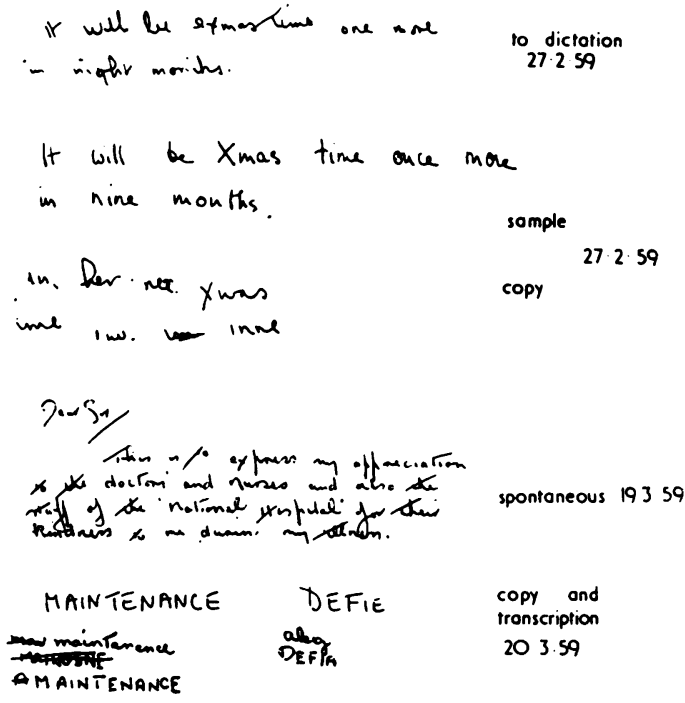

FIG. 2.-Samples of writing by the patient R.H. 
TABLE IV

PROGRESSIVE IMPROVEMENT OF WRITING IN CASE R.H.*

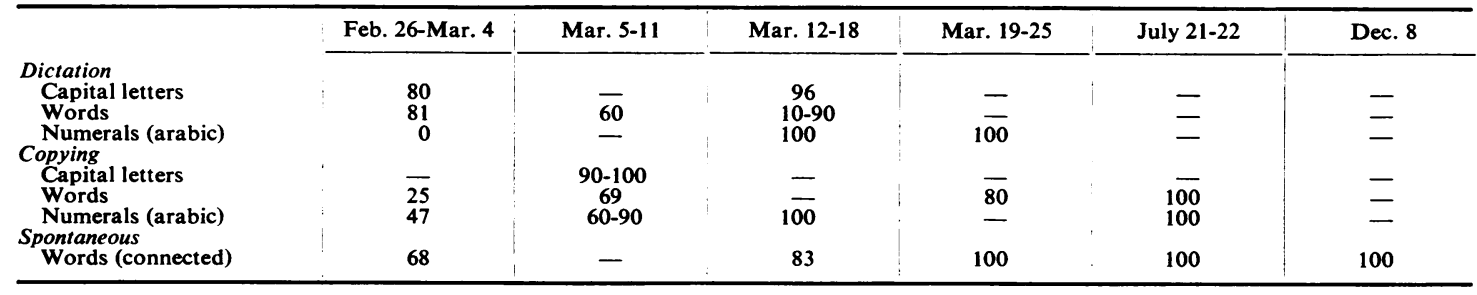

* The figures represent the percentage of correct responses.

TABLE V

PROGRESSIVE IMPROVEMENT OF PERCEPTION IN CASE R.H.*

\begin{tabular}{|c|c|c|c|c|}
\hline & February 26-March 4 & March 5-11 & March 12-18 & July 21-22 \\
\hline $\begin{array}{l}\text { Sorting letters } \\
\text { Sorting colours } \\
\text { Naming colours } \\
\text { Selecting given colour } \\
\text { Counting beads } \\
\text { Visual-spatial } \\
\text { Construction }\end{array}$ & $\begin{array}{c}98 \\
100 \\
70 \\
80 \\
100 \\
\text { Poor } \\
\text { Poor }\end{array}$ & $\begin{array}{r}96 \\
100 \\
80 \\
90 \\
\text { Fair } \\
\text { Fair }\end{array}$ & $\begin{array}{l}\overline{100} \\
100 \\
90 \\
\overline{\text { Fair }} \\
\text { Good }\end{array}$ & $\begin{array}{l}100 \\
100 \\
100 \\
= \\
-\end{array}$ \\
\hline
\end{tabular}

*The figures represent the percentage of correct responses.

Despite his disorder of reading the patient was able to sort letters almost perfectly. Fifty solid and variously coloured capital letters were scattered at random over a table. These letters lay rotated in all directions but never upside down and the patient was asked to arrange them into groups according to their shape or identity. $\mathrm{He}$ made only one error (98\% correct) on March 2 and two errors $(96 \%$ correct) on March 5 . His mistakes consisted in creating too many groups. Thus both on March 2 and March 5 a green letter $S$ was not placed in the same group as two orange letters $\mathrm{S}$, and on March 5 an orange letter $M$ was not grouped together with yellow and green letters $M$.

His ability to identify colours was moderately impaired. When asked to name the colour of various objects (wools, beads, solid letters, etc.) he was correct in $70 \%$ of attempts on February 28 , in $80 \%$ on March 11 , and in $100 \%$ on March 16 and July 21 . His scores did not differ markedly when he was asked to select from a group an object of a given colour $(80 \%$ correct on February 28, 90\% on March 11 and March 16, and $100 \%$ on July 21 ). On December 8 he still mistook red for green. By contrast he made no mistakes either on February 27 or thereafter when he was asked to sort various kinds of objects according to their colour. He also passed Holmgreen's colour matching test successfully on March 3 . He stated that his ability to visualize colours was unchanged.

Visuo-spatial Perception and Construction.-The patient gave no evidence of unilateral spatial neglect (except initially when reading, as already described). Thus on February 28 he was able to count scattered beads without error and he bisected lines on March 2 with fair accuracy under various conditions of fixation. His drawings were poor on February 27, improved on March 4, and good on March 16, with a tendency towards improved performance when he was asked to copy from a model rather than draw from memory. His performance on the papercutting test (Terman scale) was only fair on March 16 (score of 1 where 2 is the maximum) and on the same date he repeatedly failed when required to indicate the part common to three overlapping figures (Abelson's test). Similarly, he was unable to make a reasonable plan of his ward (on February 28) or to draw an adequate map of England (on March 12) or to score better than $70 \%$ correct on the cube-analysis test of the Terman scale (on March 20). When questioned about his home and about the route between well-known landmarks it became evident (on both February 28 and March 12) that his topographic memory was severely impaired. His performance on constructional tests such as block designs and match-stick designs improved from poor on March 2 to good on March 19, again with some added improvement when a model was made available.

\section{Summary of Case Report}

The ability of this patient to read was at first virtually lost, although his writing was less severely affected and his spoken speech only mildly disturbed. A right homonymous hemianopsia was the salient finding on neurological examination and the presence of an arteriovenous malformation in the left occipital region was demonstrated by means of left carotid angiography.

After admission, it was possible to assess his performance on a wider range of tests. Additional disorders, for example in the identification of colours and in calculation, were demonstrated. The rapid improvement of his performance over a period of four weeks was followed in detail. He was again seen at nine months after the first onset, when the disturbance of reading, though 
much improved, was still the most marked residual disability.

\section{Survey of Series of Cases}

Of the patients seen by the Department of Psychology 700 consecutive referrals were reviewed. The cases showing one or more disorders of language (dysphasia, dyslexia, or dysgraphia) were made the subject of further analysis. If the onset of illness was before 6 years of age, if there were left-handed tendencies, or if the language functions were not adequately tested, the case was excluded from this survey. A total of 35 cases with language disorders remained. The degree of impairment was graded from 0 to 4 plus, ranging in order from normal to slight, moderate, severe, or extreme impairment, separately for spoken speech, reading, and writing. For the purpose of this survey (concerned with the differential breakdown of spoken speech, reading, and writing) no attempt at localization of the pathology was made.

Table VI lists the type and degree of deficit in the

TABLE VI

SURVEY OF TYPES AND DEGREE OF LANGUAGE DISABILITY

\begin{tabular}{|c|c|c|c|c|c|}
\hline $\begin{array}{l}\text { Case } \\
\text { No. }\end{array}$ & Initials & $\begin{array}{c}\text { Hospital } \\
\text { No. }\end{array}$ & Dysphasia & Dyslexia & Dysgraphia \\
\hline $\begin{array}{r}1 \\
2 \\
3 \\
4 \\
5 \\
6 \\
7 \\
8 \\
9 \\
10 \\
11 \\
12 \\
13 \\
14 \\
15 \\
16 \\
17 \\
18 \\
19 \\
20 \\
21 \\
22 \\
23 \\
24 \\
25 \\
26 \\
27 \\
28 \\
29 \\
30 \\
31 \\
32 \\
33 \\
34 \\
35\end{array}$ & $\begin{array}{l}\text { A.H. } \\
\text { R.W. } \\
\text { M.E. } \\
\text { C.S. } \\
\text { C.S. } \\
\text { W.W. } \\
\text { W.F. } \\
\text { C.G. } \\
\text { H.H. } \\
\text { R.C. } \\
\text { H.L. } \\
\text { A.H. } \\
\text { J.H. } \\
\text { H.W. } \\
\text { E.S. } \\
\text { P.B. } \\
\text { E.W. } \\
\text { J.S. } \\
\text { A.L. } \\
\text { S.K. } \\
\text { M.G. } \\
\text { F.L. } \\
\text { Y.H. } \\
\text { M.M. } \\
\text { M.P. } \\
\text { L.R. } \\
\text { J.P. } \\
\text { M.T. } \\
\text { M.W. } \\
\text { P.B. } \\
\text { F.S. } \\
\text { C.H. } \\
\text { H.T. } \\
\text { S.P. } \\
\text { W.C. }\end{array}$ & $\begin{array}{r}36459 \\
9720 \\
7812 \\
11930 \\
1874 \\
37475 \\
12672 \\
5573 \\
8545 \\
6699 \\
12668 \\
33581 \\
7529 \\
3705 \\
5522 \\
72438 \\
37018 \\
2890 \\
38223 \\
4432 \\
42437 \\
548 \\
3332 \\
13136 \\
13234 \\
14005 \\
42239 \\
25487 \\
43346 \\
81353 \\
1944 \\
42385 \\
49517 \\
77531 \\
13721\end{array}$ & $\begin{array}{l}0 \\
+ \\
++ \\
++ \\
+ \\
+ \\
++ \\
++ \\
+++ \\
+++ \\
++++ \\
++++ \\
+++ \\
+++ \\
+++ \\
++ \\
++ \\
++ \\
++ \\
+ \\
+ \\
+ \\
+ \\
+ \\
+ \\
+ \\
+ \\
+ \\
+ \\
+ \\
++ \\
++ \\
++ \\
++ \\
++\end{array}$ & 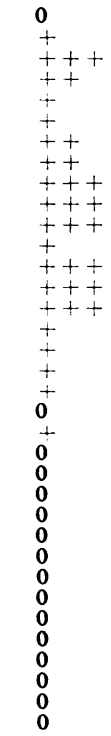 & $\begin{array}{l}++++ \\
+++ \\
+++ \\
+++ \\
+ \\
+ \\
++ \\
++ \\
+++ \\
+++ \\
++ \\
++ \\
++ \\
++ \\
\mathbf{0} \\
++ \\
++ \\
+ \\
+ \\
+ \\
\mathbf{0} \\
\mathbf{0} \\
\mathbf{0} \\
\mathbf{0} \\
\mathbf{0} \\
\mathbf{0} \\
\mathbf{0} \\
\mathbf{0} \\
\mathbf{0} \\
\mathbf{0} \\
\mathbf{0} \\
\mathbf{0} \\
\mathbf{0} \\
\mathbf{0} \\
\mathbf{0}\end{array}$ \\
\hline
\end{tabular}

Dysphasia comprises disorders of spoken speech in its receptive, expressive, or nominal aspects.

Dyslexia and dysgraphia indicate disorders of reading aloud and writing on paper.

0 indicates normal. + indicates slight impairment. ++ indicates moderate impairment. +++ indicates severe impairment. ++++ indicates extreme impairment.
35 patients. Dyslexia alone was not observed in this group, but there was one case of dysgraphia without associated disorder of language. Dysphasia was found as an isolated language disability in 14 cases.

Two sub-modalities of language were affected in three cases. Dysphasia was associated with dyslexia in two of these and with dysgraphia in the third. All three functions were impaired in 17 cases.

When the degree of impairment was considered, dyslexia and dysgraphia, alone or together, were more severe than dysphasia in four cases. Of these, dysgraphia was more marked than dyslexia in two cases. In one case it was the sole disability, and in the fourth case the dysgraphia and dyslexia were of equal severity. The degree of impairment of spoken speech, reading, and writing was found to be equal in six cases. However, in 25 cases the dysphasia was more marked than the dyslexia or the dysgraphia. Of these, reading is more severely impaired than writing in five cases, whereas writing is more severely affected than reading in four.

Of the most interest to us are the four cases in which reading and/or writing were more severely disturbed than spoken speech.

\section{Subsidiary Cases}

Case 1.-A.H. (N. H. 36459, under the care of Mr. H Jackson and Dr. M. Critchley), a 56-year-old man, i whom the only significant finding was a Gerstman' syndrome and constructional apraxia. Results of ventriculography indicated a left fronto-parietal exê을 panding lesion. At necropsy 10 weeks after the exo amination of language functions, a right bronchiaf. carcinoma was found with multiple metastases in bot cerebral hemispheres.

Case 2.-R.W. (N.H. 9720, under the care of Dr. D. Williams), a man, aged 30 years, had no significant physical findings. An interesting observation was the absence of constructional apraxia. The E.E.G. examination showed a mild abnormality, more pronounced on the left. Cerebral venous thrombosis was the presumed diagnosis.

Case 3.-M.E. (N.H. 7812, under the care of Mr. W. McKissock), a 51-year-old woman had, on physical examination, a visual acuity of $6 / 24$ bilaterally. Other findings, all on the right side, included a lower facial weakness, increased tendon reflexes, an extensor plantar response, increased tone in the ankles, and cortical sensory loss. She was also dyspraxic. At operation a left intraventricular meningioma extending into the parieto-occipital area was removed.

Case 4.-C.S. (N.H. 11930, under the care of Dr. P. Martin), a 62-year-old man, had marked dementia. No 을 abnormal signs of diagnostic value were found on $\mathrm{N}$ physical examination. His E.E.G. showed a widespread $\Omega$ abnormality, greatest in the left posterior temporal $N$ 
region. Gross bilateral cortical atrophy was revealed by air encephalography.

\section{Discussion}

It would appear to be established that reading or writing (or both together) may on occasion be more severely disturbed as a result of brain damage than is spoken speech. Two questions immediately arise. First, is the dyslexia or dysgraphia in such cases merely secondary to another more basic disorder (such as defective vision) so that it cannot properly be classified as a defect of language? Secondly, can we draw any inferences concerning the organization of language from the finding of the occasional "independence" of dyslexia and dysgraphia from dysphasia?

In answer to the first question we would propose that reading and writing were disordered at the level of symbolic function in our main case (R.H.). Similarly, the disorders of reading and/or writing at least in the subsidiary cases 1-3 seem to us to reflect genuine symbolic disturbances. We are of course aware that in our case R.H. there were present in addition to the dyslexia or dysgraphia also associated disabilities involving vision (such as the hemianopsia and the defective identification of colours), some aspects of executive function (construction) and involving also but to a minor degree more general intellectual capacities (abstraction and memory). It is, however, our opinion that these associated disabilities are unlikely to have given rise to the dyslexia and dysgraphia. This view derives support from two lines of evidence. First, from the careful analysis of the pattern of psychological breakdown. Thus, to take only an example, the severe initial defect in identifying single letters was associated with an impairment of oral spelling (which cannot be attributed to spatial or constructional disorders) but also with the preseveration of the ability to identify musical notation (which excludes a general defect of vision or oculomotor control). Secondly, in our experience a comparable or even more severe impairment of vision, executive functions, or of intellectual capacity has not been found to be invariably or even frequently associated with dyslexia or dysgraphia in other cases. We would therefore hold with Holmes (1950), Symonds (1953), and Brain (1955) that a disorder of reading, considered as a partial agnosia or symbolic loss, may on occasion be predominant over alterations of spoken speech, and similarly that a true dysgraphia may appear as more pronounced than the concomitant dysphasia (if any). We feel unable, however, to offer a more detailed explanation of the nature of the symbolic loss shown by our patient.

Turning to the second question, concerning the organization of the language functions, our inferences must remain more tentative. It is clear from our survey that spoken speech is more vulnerable than reading or writing. Thus 34 of the 700 unselected cases $(4.9 \%)$ had dysphasia against $19(2.7 \%)$ with dyslexia and an equal number with dysgraphia. Our survey also indicates that dysphasia, dyslexia, and dysgraphia are associated (disregarding varying grades of severity) in a large proportion of cases, namely in 17 of 35 cases with some disturbance of language, or in $48.6 \%$. These findings taken by themselves would suggest a hierarchical organization, such that reading and writing might be considered to lack their individual, anatomically independent, neural systems, and to suffer disorder as a consequence of a loss of spoken speech. Such a view cannot, however, incorporate the further evidence that dyslexia or dysgraphia (or both) may occasionally (in $0.6 \%$ of our 700 cases, or in $11.4 \%$ of the 35 cases of language disturbance) be more marked than dysphasia. An even higher incidence of predominant reading disability $(13 \%)$ has been reported by Brown and Simonson (1957) in their series of 100 aphasic patients. It would therefore seem a reasonable, though not inevitable conclusion, that the neural systems, which, when interrupted give rise to dyslexia and dysgraphia, are despite their considerable overlap with the more extensive neural system concerned with spoken speech to some extent independent of it.

\section{Summary}

The relationship between the degree of impairment (if any) of reading, writing, and spoken speech has been examined in neurological cases.

One case in which severe dyslexia and moderate dysgraphia were associated with only slight dysphasia is described. The improvement of this patient's performance on language tests is followed in detail over a period of nine months.

A survey of 700 unselected neurological cases indicates that in only one case out of 35 showing some language disorder was dyslexia or dysgraphia found as the sole disability. However, when the degree of impairment was considered, dyslexia and dysgraphia, alone or together, were more səvere than dysphasia in four cases.

The implications of such occasional "independence" of dyslexia and dysgraphia from dysphasia are briefly discussed.

We are greatly indebted to Dr. E. A. Carmichael who brought the case of R.H. to our attention on the day of admission and permitted us to study and publish the case and has given us generous and valuable help in the preparation of this paper; to Dr. Macdonald Critchley, Mr. Harvey Jackson, Dr. Purdon Martin, Mr. Wylie 
McKissock, and Dr. Denis Williams we are grateful for permission to refer to the subsidiary cases 1-4; and to the physicians and surgeons of the National Hospital for permission to study their patients. The quantitative analysis of 700 cases was made possible through the cooperation and help of Dr. J. McFie. To Mr. S. Russell we are greatly indebted for his investigation of the reading of musical notation in this patient.
REFERENCES

Beringer, K., and Stein, J. (1930). Z. ges. Neurol. Psychiat., 123, 472 . (Q Brain, W. R. (1955). In Neurology, 2nd ed., Vol. 3, by Wilson, S. A. Kinnier, ed. A. N. Bruce, Butterworth, London.

Brown, J. R., and Simonson, J. (1957). Neurology, 777 .

Critchley, M. (1953). The Parietal Lobes. Arnold, London.

Gerstman, J. (1940). Arch. Neurol. Psychiat. (Chicago), 44, 398.

Holmes, G. (1950). Folia psychiat. (Amst.), 53, 279.

Martin, J. P. (1954). Proc. roy. Soc. Med., 47, 293

Symonds, C. (1953). J. Neurol. Neurosurg. Psychiat., 16, 1

Warrington, E., and Zangwill, O. L. (1957). Ibid., 20, 208.

\section{THE MAY (1960) ISSUE}

The May (1960) issue contains the following papers:-

Relief of Pain and Paraesthesiae by Nerve Block Distal to a Lesion. R. E. Kibler and P. W. Nathan.

Spasticity and Rigidity: An Experimental Study and Review. Geoffrey Rushworth.

The Effect of Changes in Serum Potassium Upon Myotonia. Peter Leyburn and John N. Walton.

Studies on Intermediate Carbohydrate Metabolism in Multiple Sclerosis. B. McArdle, I. C. K. Mackenz and G. R. Webster.

The Surgical Approach to Thoracic Intervertebral Disc Protrusions. Allan Hulme.

Lumbar Disc Protrusions in Pregnancy. J. E. A. O'Connell.

The Influence of a Vascular Factor on the Distribution of Symmetrical Cerebral Calcifications. R. M. Norman and $\mathbf{H}$. Urich.

Ascending Nerve Roots. J. D. Reid.

Abnormality of the Blood-cerebrospinal Fluid Barrier of Patients Suffering from a Depressive Illness. A. J. Coppen.

Adaptation to Postural Change in Psychiatric Patients. A. G. Mezey and P. H. Melville.

The Specificity of Reserpine in the Treatment of Schizophrenia in Identical Twins. S. Benaim.

Malignant Change in an Intracranial Epidermoid. S. I. Davidson and J. M. Small.

Giant Mucocele of the Frontal Sinus. George W. Smith and Marcelino Chavez.

Book Reviews.

A number of copies are still available and may be obtained from the Publishing Manager, British Medical Association, Tavistock Square, W.C.1, price 17s. $6 d$. 